\title{
التكشيف آلآلى
}

\section{أسماء شروت بيومي عبده (*)}

تمهيد:

يشهر العصر الحالي تطورات متلاحقة في شتى ميادين المعرفة، وعلى تلى رأسها مجال تنظيم واسترجاع المعلومات؛ حيث تلعب تكنولئوجيا المئي المعلومات

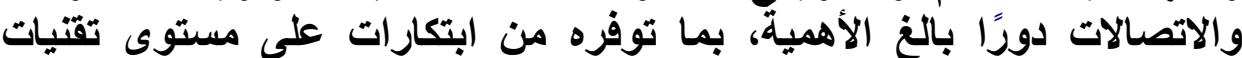

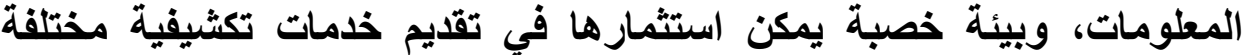

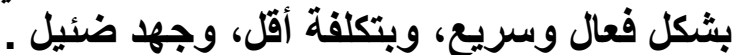
فبمجرد ظهور تطبيقات الحاسب الآلي ونجاحها في العديد من المجالات،

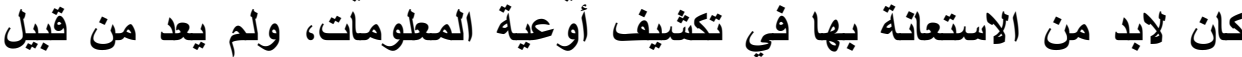
الاختيار، بل من الضروري والمحتمى استخدام تكنولوجيا الحاسبات، والإتترنت، والنظم الخبيرة التي حققت طقرة ونقلة نوعية في هذا المجال.

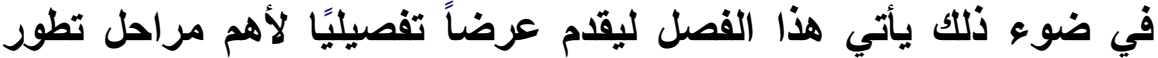

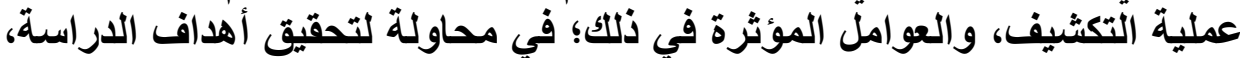
والإجابة عن تساؤلاتها فيما يتعلق بماهية التكشيف الآلي، وبرامجهاه، والفئ والفوائد

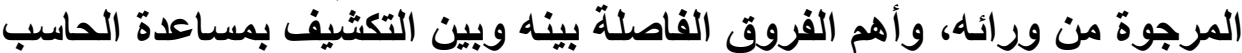

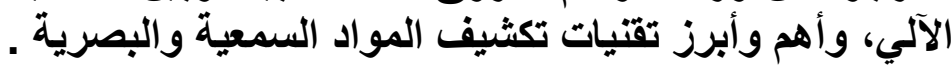

\section{Indexing : التكشيف}

تُشكل عملية التكشيف عنصرًا حيويًا في حلقة الاتصال بين منشى ملثى المعلومات والمستفيا النهائي منها؛ حيث تعمل على تلفئ تنظيم محتوى الإنتاج

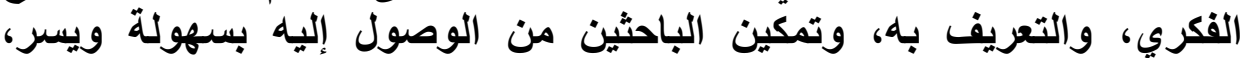

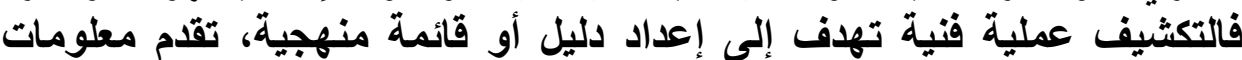

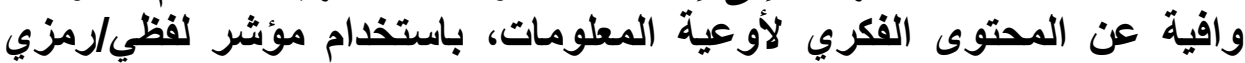

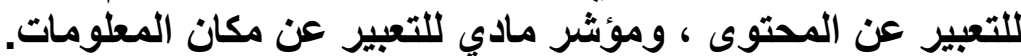

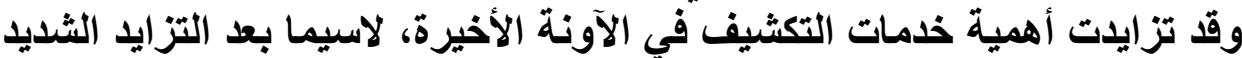

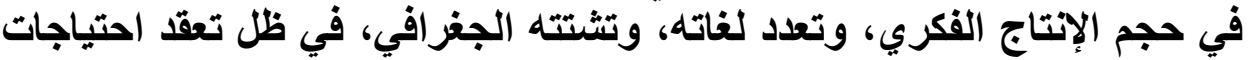

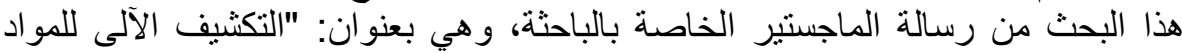

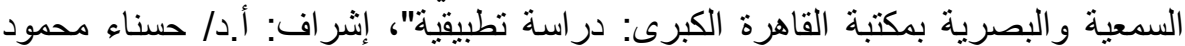
محجوب ـ كلية الآداب ـ جامعة المنوفية \& دالكية نادية عبدالعزيز الصواف ـ ـ كلية الآداب ـ 
الباحثين، وتغير أنماط الطلب على الإنتاج الفكري، مما استاعى ضرورة توافر أشكال جديدة من الكثافات تواكب المتطلبات الجديدة في ظل هذه المتغيرات.

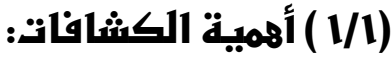

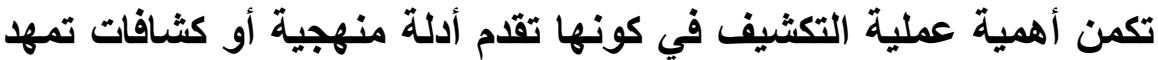

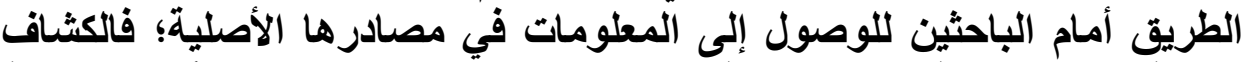

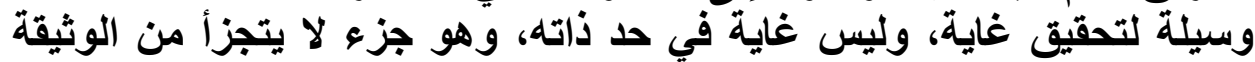

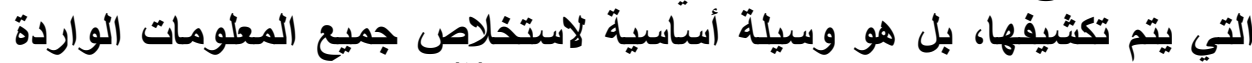

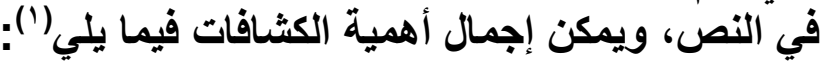

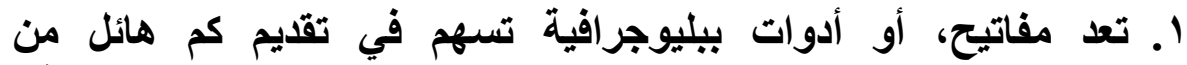

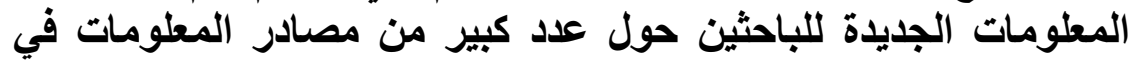

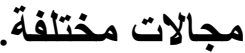

r. تعمل كحلقة اتصال تربط بين الباحث ومصادر المعلومات في مجال تخصصه. r. تساهم في تقليل الجهد، والزمن المبذول لاسترجاع المعلومات من مصادر ها الأصلية.

:

هنالك عدة أغراض، ووظائف تسعى الكثافات إلى تحقيقها، يمكن إيجازها

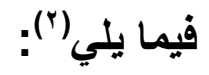

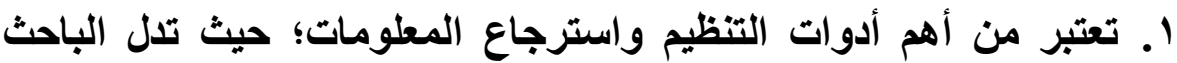

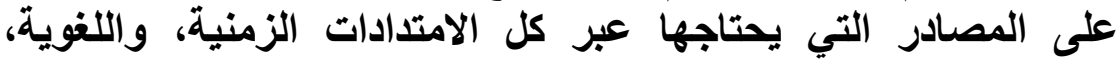

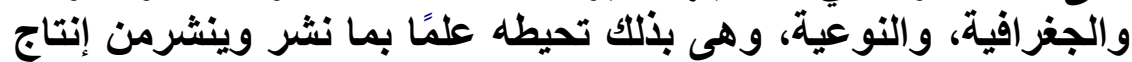
فكرى يتعلق بإهتماماته.

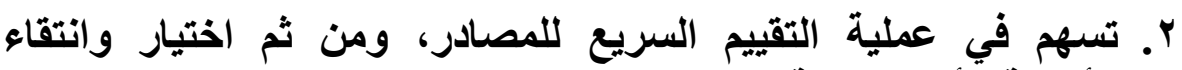

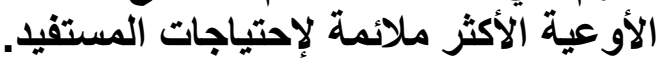
r. أداة سهلة الاستخدام، تعين الباحث على التحقق من معلوماتهاته، والعمل على استكمالهها أو تصحيحها.

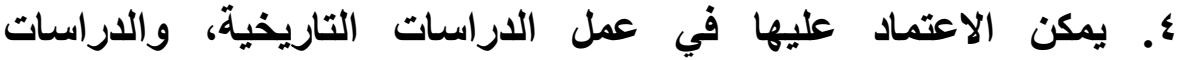

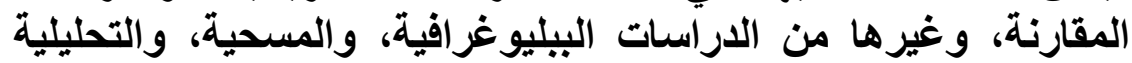

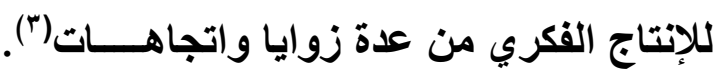




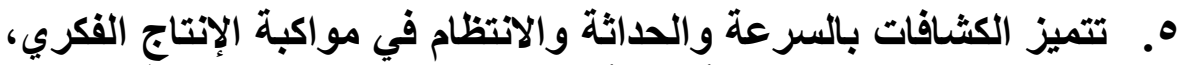

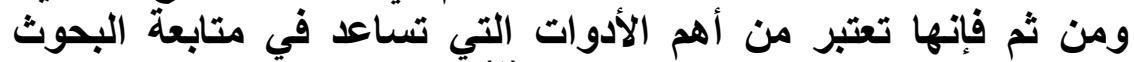

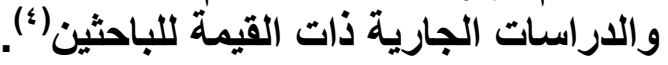

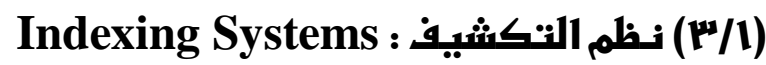

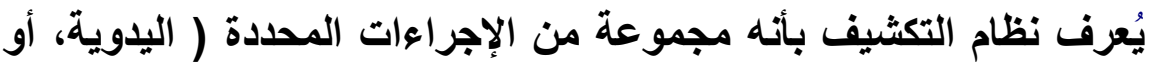

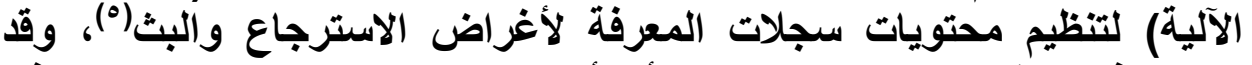

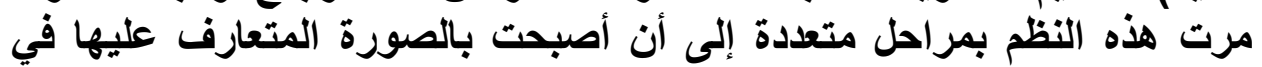

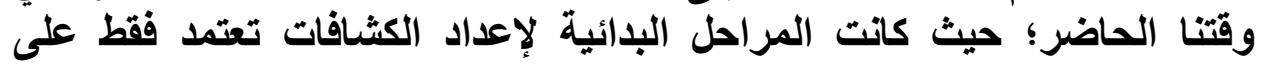

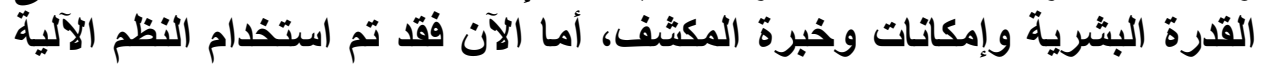

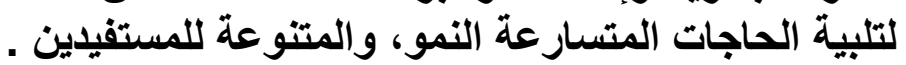

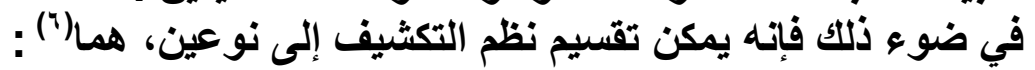

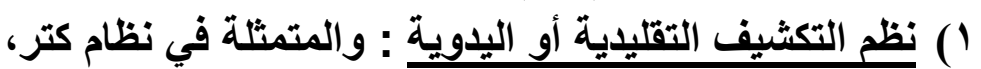

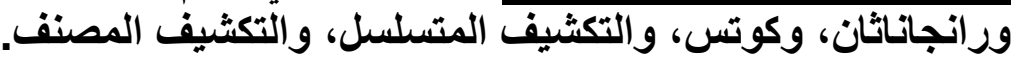

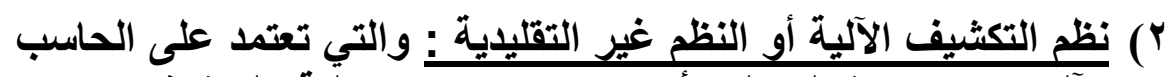

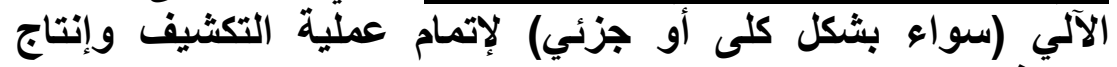
الكثافات.

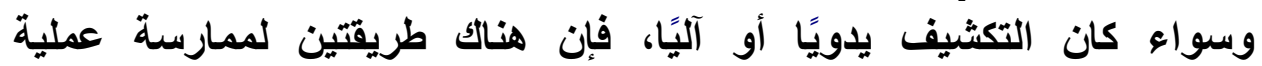

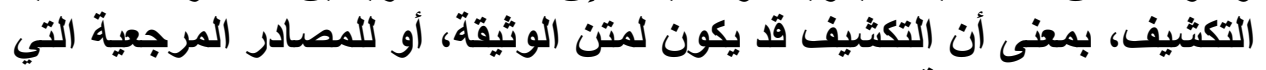
اعتمدت عليها الوثيقة أنة التئة

\section{أوًاً : تكشيف متن الوثيقة : وهو نوعين :}

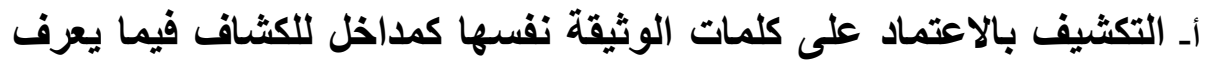

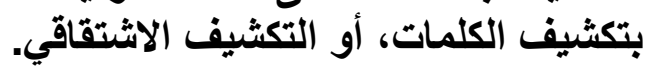

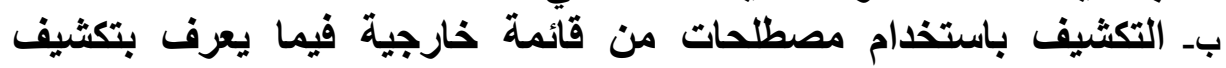

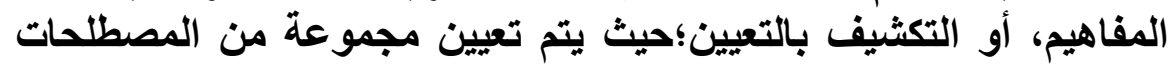

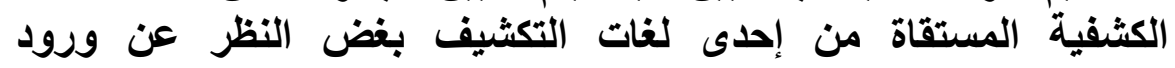

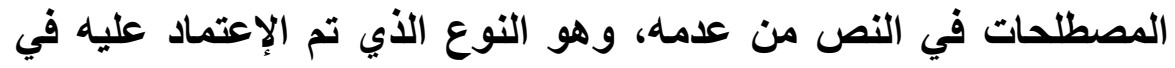
إعداد الكشاف الآلي موضوع الدار اسة. 


\section{ثنانيًا : تكشيف المصادر المرجهية التير اعتمهت عليها الوثيقة :}

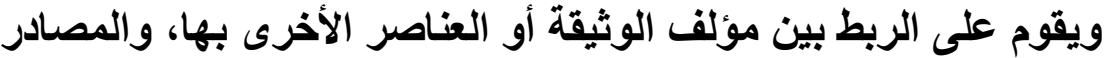

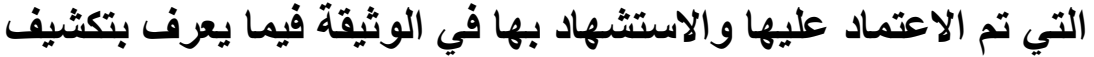
الاستثهادات المرجعية.

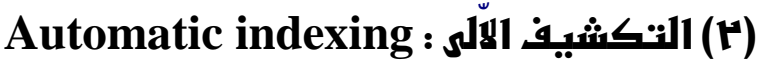

إذا كان التكثيف عبارة عن نظام منهجي يستخدم لتمثيل المعلومات داخل

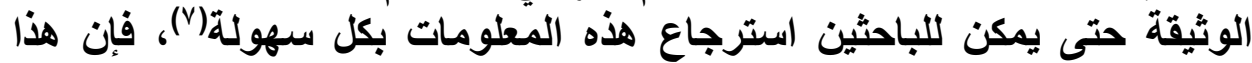

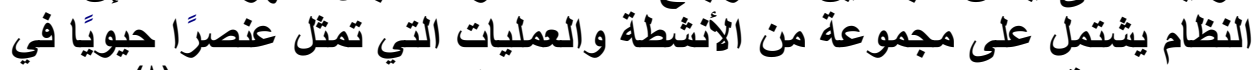

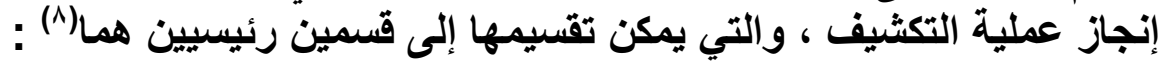

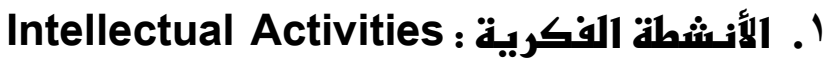

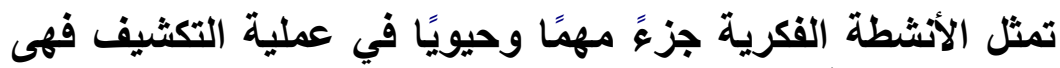

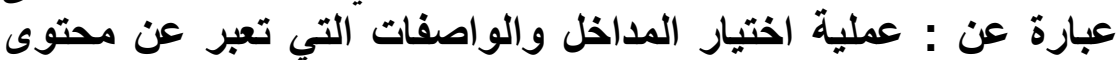

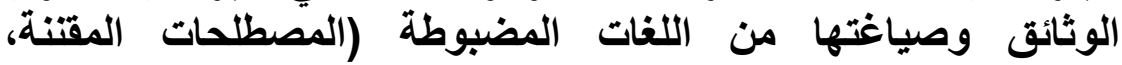
والكلمات المفتاحية المضبوطة) ،أو من اللغة الطبيعية بغرض المنات إنثاء نظام يصلح لاسترجاع المعلومات.

\section{Mechanical Activates :}

وهى تلك الأنشطة التي يمكن أن تقوم بها الحاسبات الآلية لإتمام

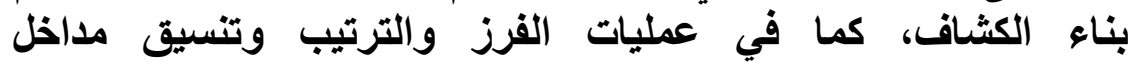

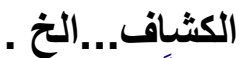
وطبقًا للتوزيع والتقيمِ السابق لأنشطة التكشيف فإنه يمكن التمبيز بين

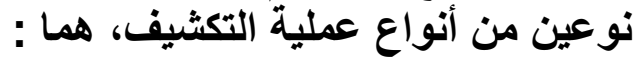

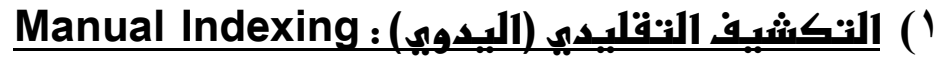

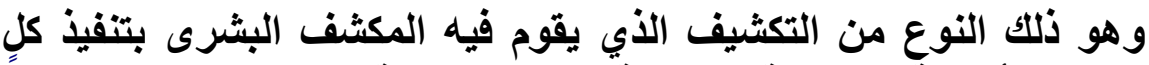

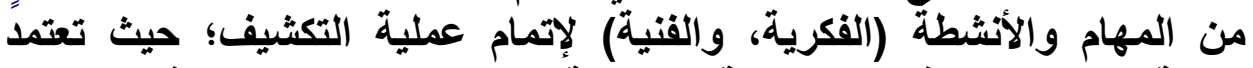

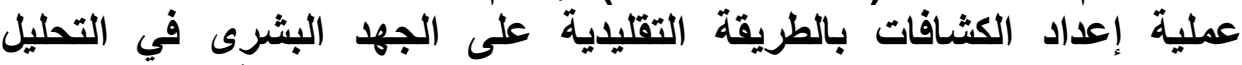

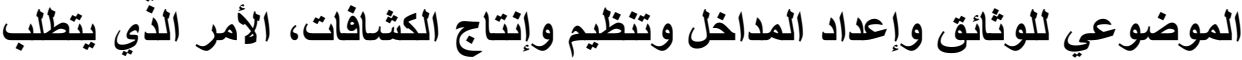

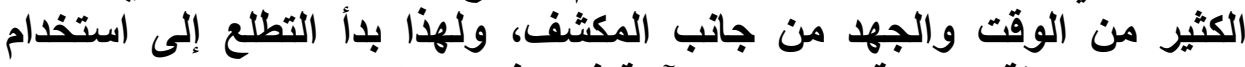
التقنيات الحديثة وخاصة الحاسبات الآلية في هذا المجال. 
Automatic Indexing ,Computer based : التكشيف آلك

Indexing

ويقصد به هنا: ذلك النوع من التكثيف الذي يتم فيه استخلام الحاسب

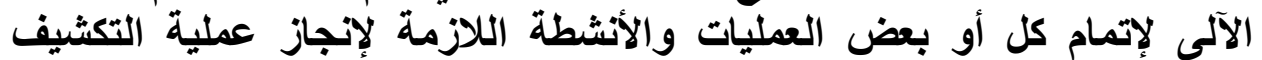

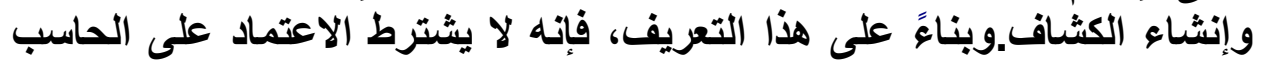

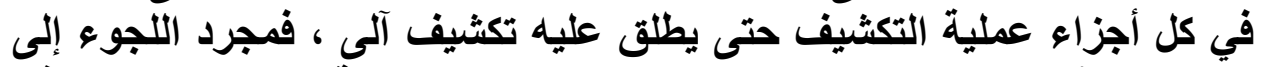

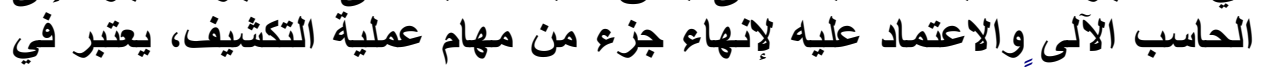

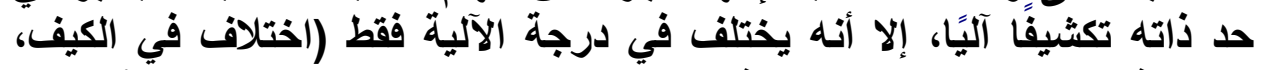
وليس في النوع) ، كما سيتضح في العرض التالي لمستويات التكثيف الآلى.

\section{: ن نشأة التكشيف الآلى}

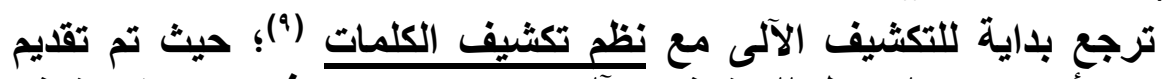

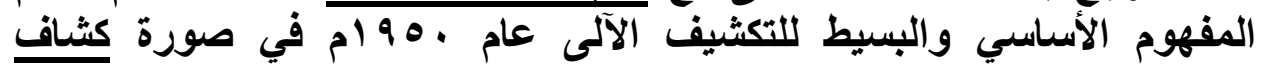

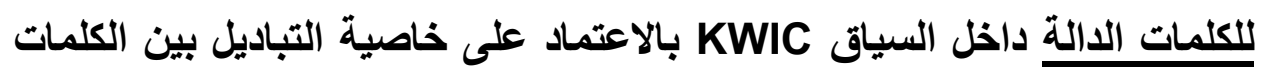

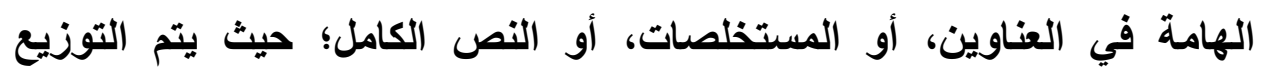

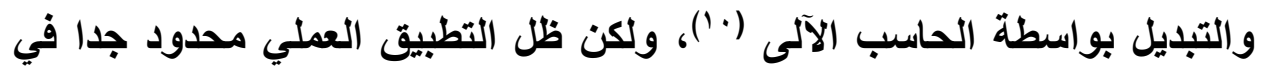

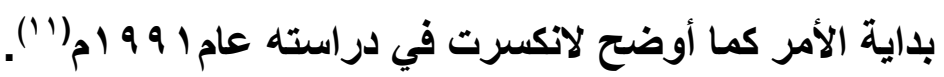

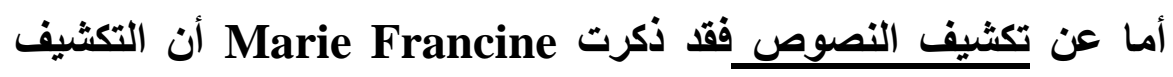

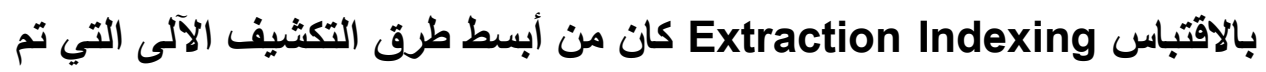

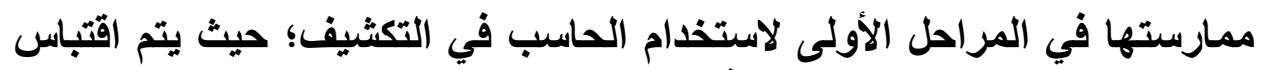

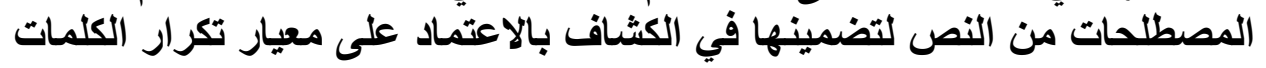

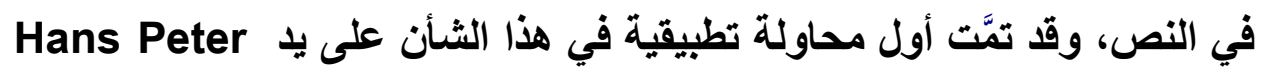

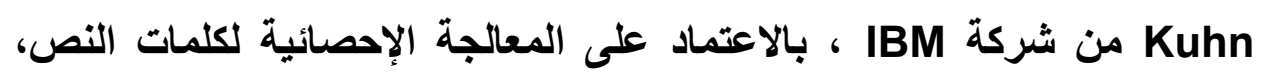

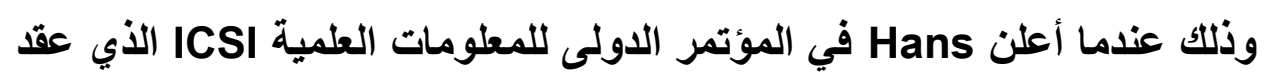

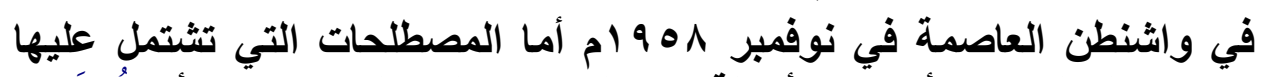

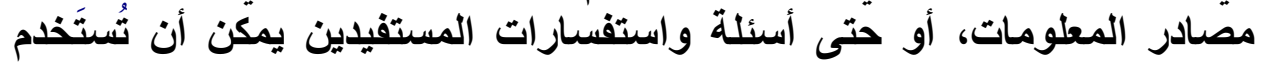
لأغراض تحليل المحتوى (ir) وفى عام البو ام طورHans برنامجًا لإعداد كثافات بالكلمات المفتاحية Chemical " لعناوين المقالات التي ترد في دورية "المستخلصات الكيميائية 
Abstract، مما دفع الباحثين إلى المضي قدمًا والاستمرار في هذه المحاولات

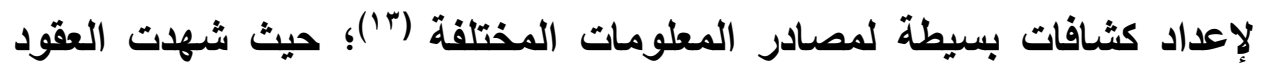

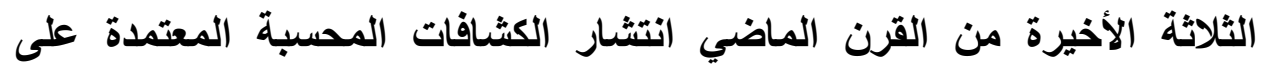
الكلمات المفتاحية (Kwic, Kwoc, Kwac) بأنواعها المختلفة ، وخاصة الأنة

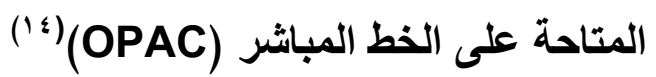

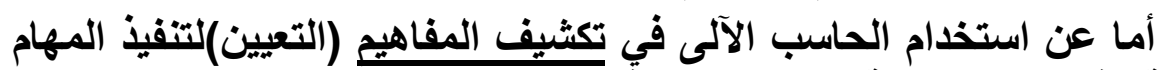

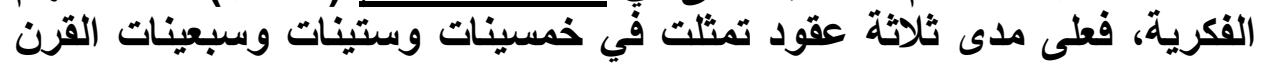

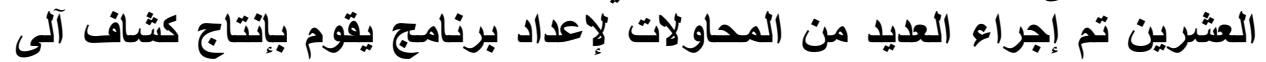

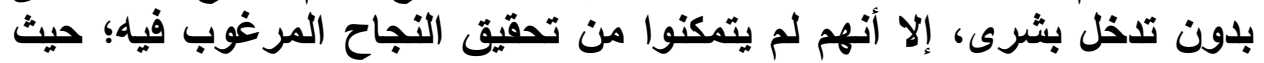

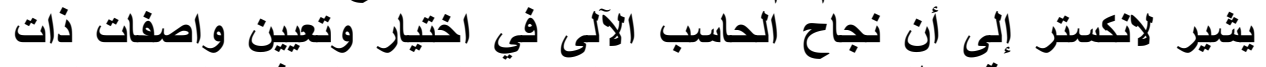

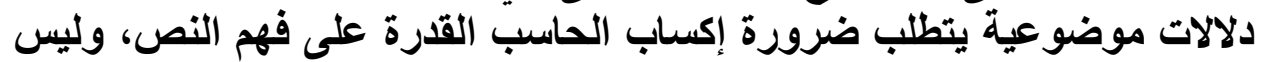

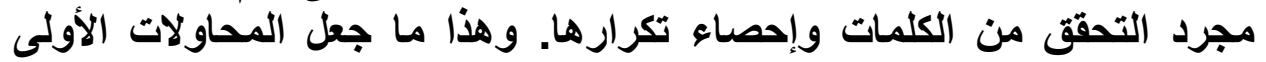

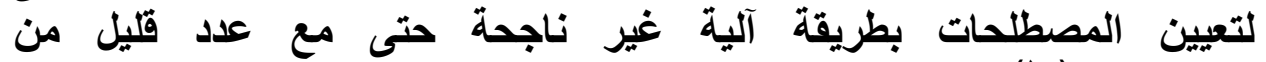

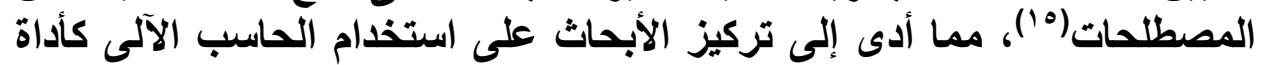

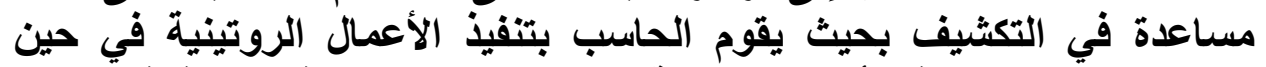

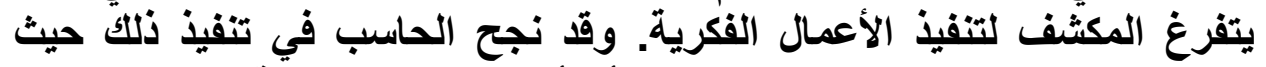

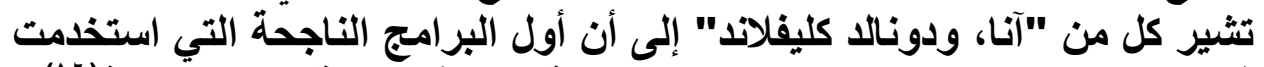

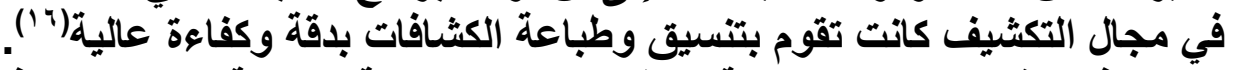

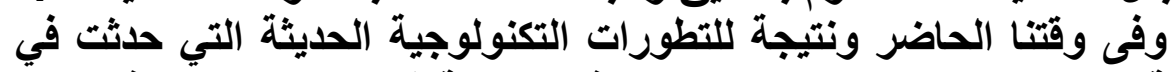

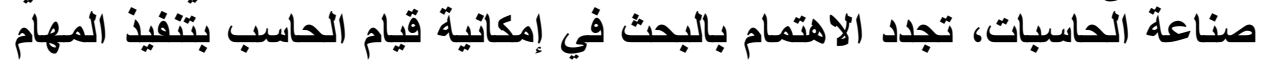

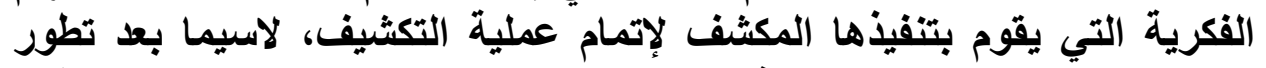

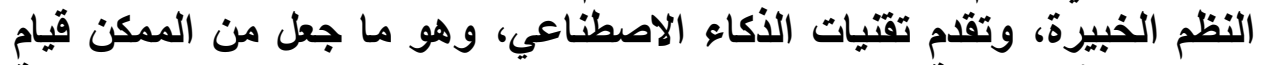

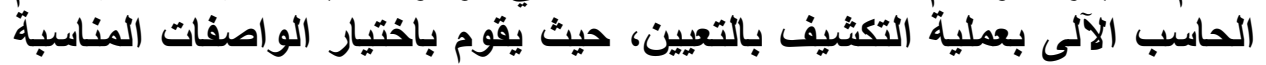

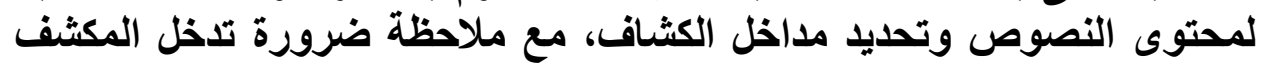

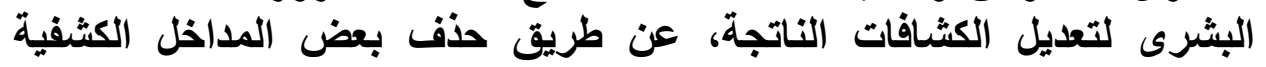

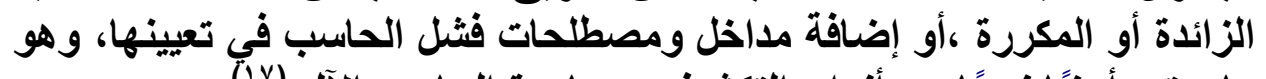

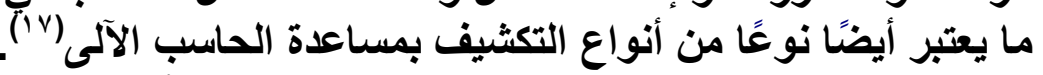

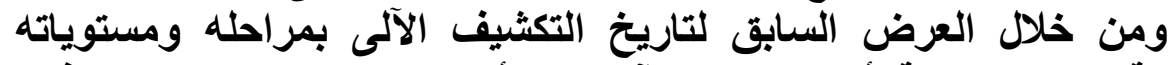

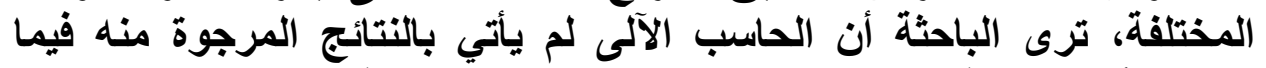

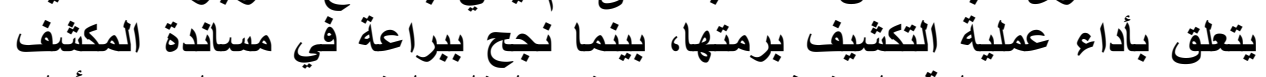

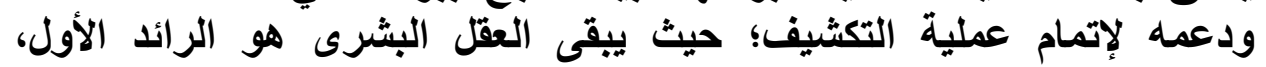

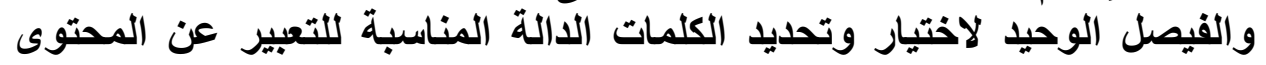
الموضوعي. 


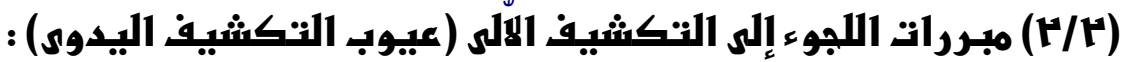

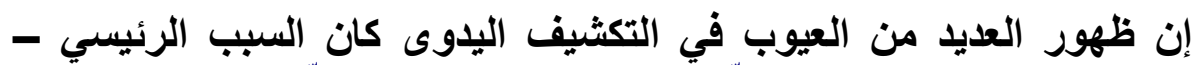

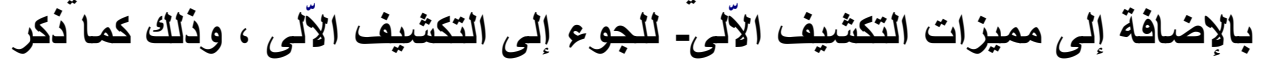

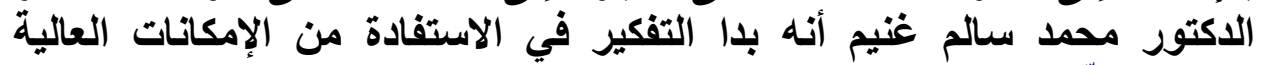

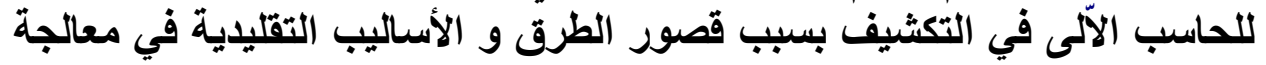

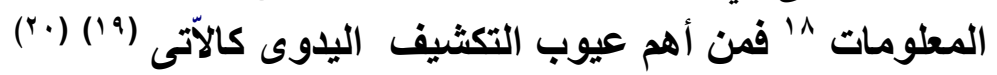

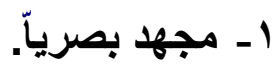$$
\text { r - يحتاج إلى تركيز شديد . }
$$

r- يعد من الأمور الباهظة التكلفة . ئركيز

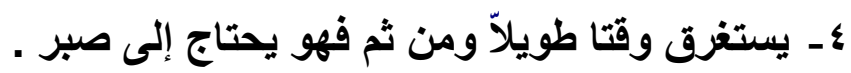
هـ صعوبة الحصول على المكثفين المهنيين المؤهلين .

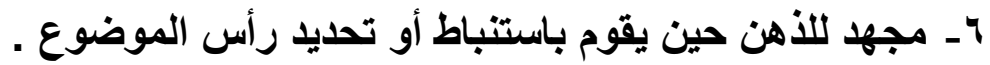

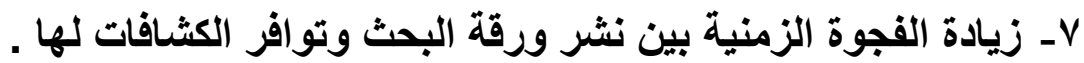

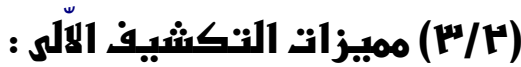

في الحقيقة أن عيوب التكثيف اليدوى تعكس مميزات التكثيف الآلى , وبالتالي التئي

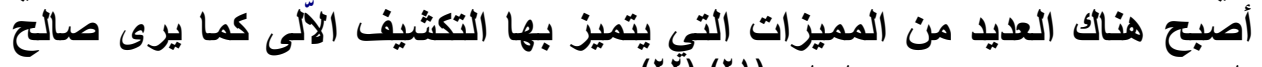

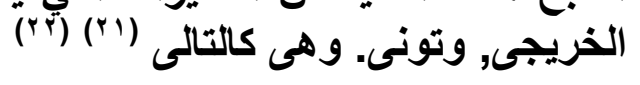

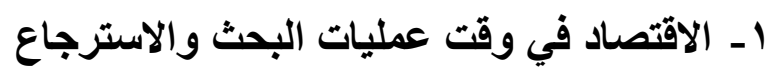

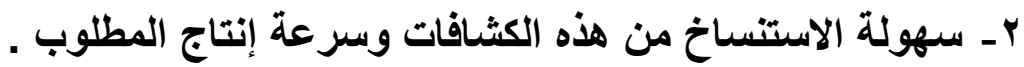

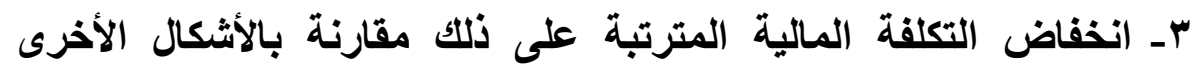

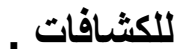

ع - سهولة الحذف والإضافة والتعديل سواء عند ملاحظه اى أخطأ بالكشاف

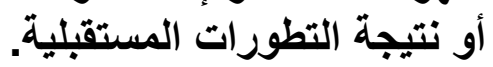

هـ أسرع من التكشيف اليدوى الأي يتم من خلال الجهد البشرى منذ سنوات المبات

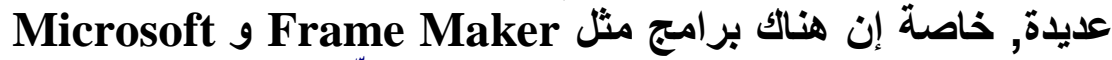
Adobe وWord

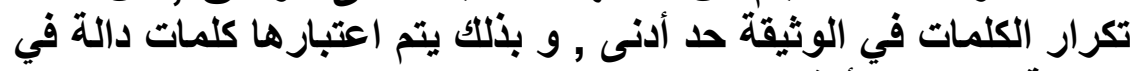

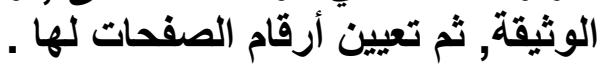




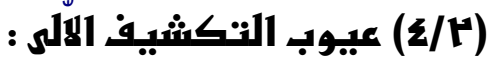

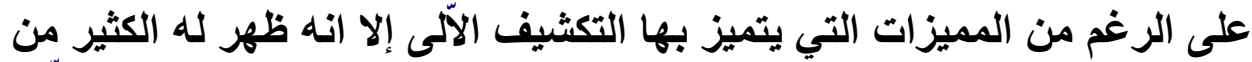

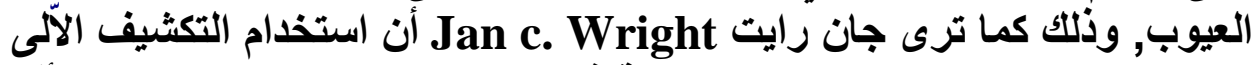
Automatic Indexer

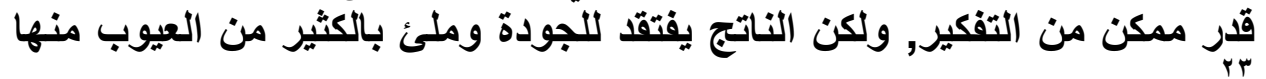

1 ـ ظهور العديد من المداخل عديمة المعنى في الكثاف الناتج مما يتطلب المبات

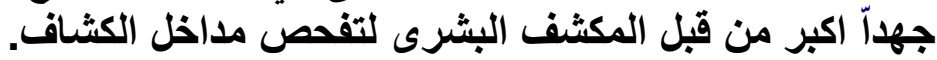

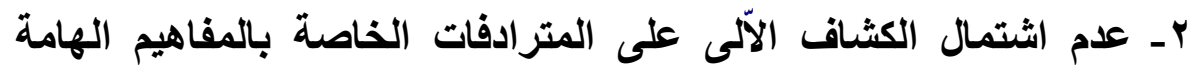
وافتقاده للإحالات .

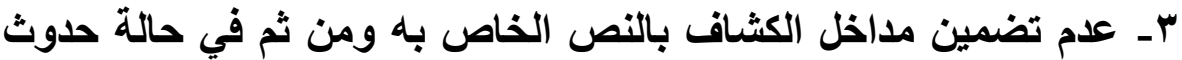

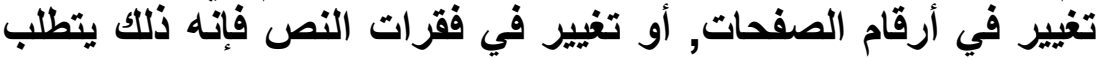

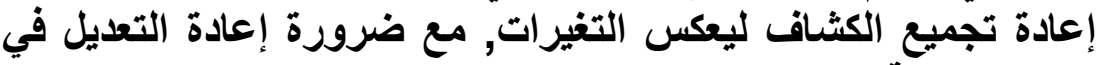

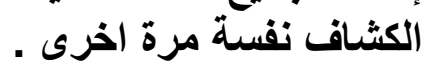

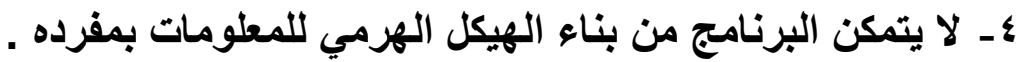

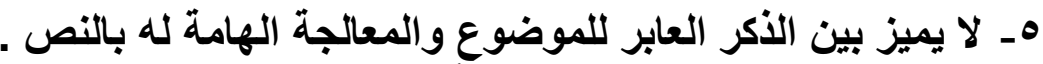
كما يرى ماسلين اكيز

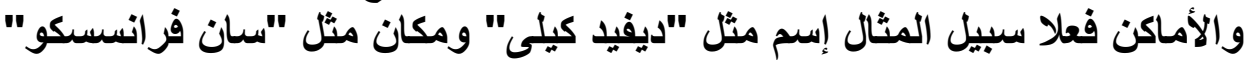

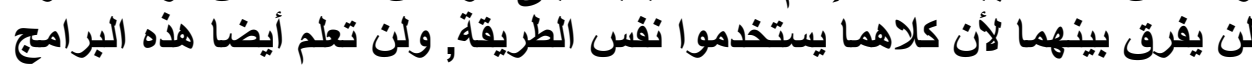

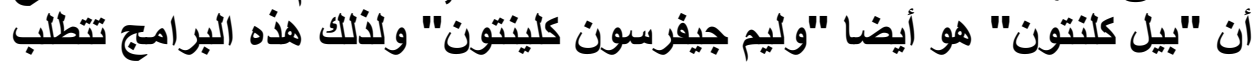

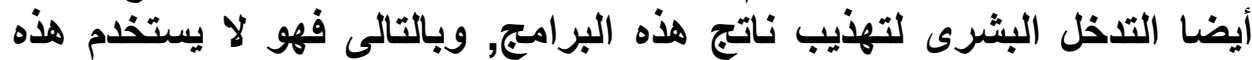

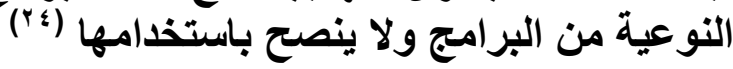
:

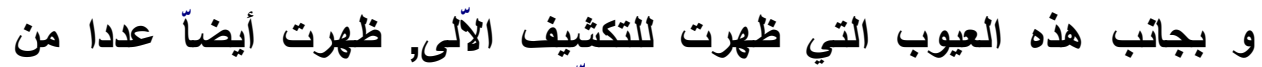
الصعوبات التي عجزت, برامج الصوب الحاسب الآلى القيام بها كما تقام في التكشيف

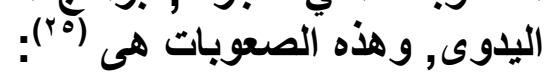

1 ـ فثل الحاسب في تنفيذ العمليات العقلية التي يتطلبها التكشيف في تحديا

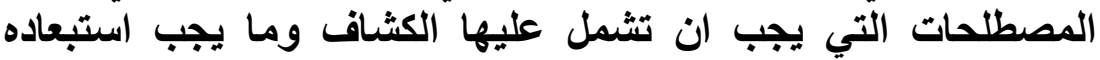

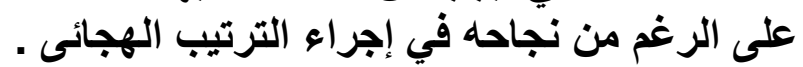

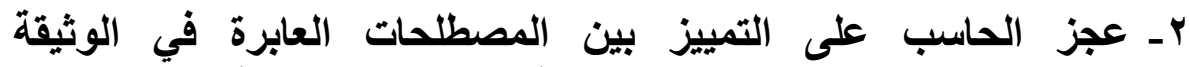
والمصطلحات التي لها مناقشات هامة بداخل نص الوثئة. 
r- عدم قدرة الحاسب على التنبؤ بالمداخل التي تثقق مع احتياجات

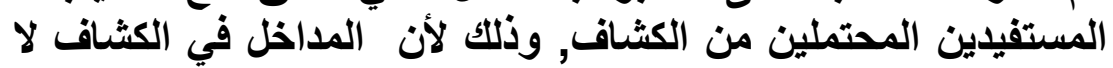

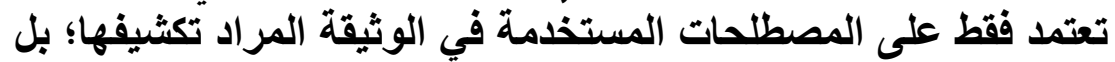
إنها تعتمد أيضا على المصطلى المات المستخدمة من قبل المستفيدين

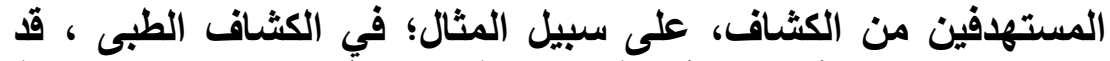

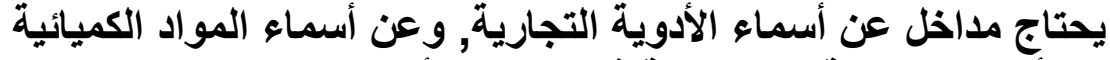

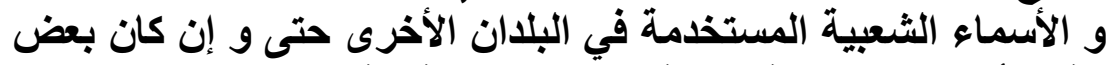

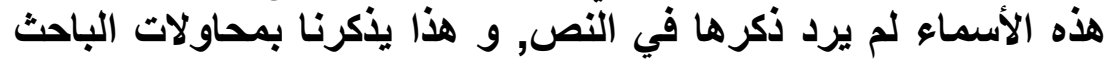

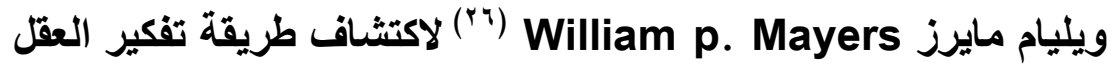

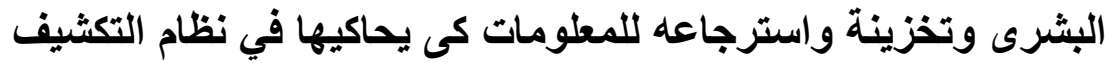

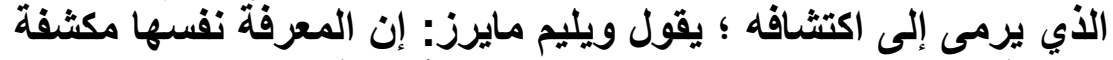

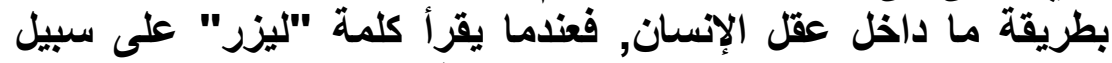

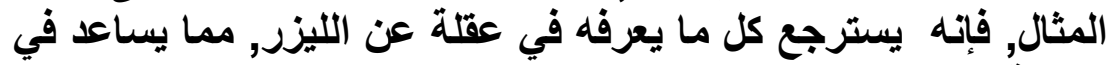

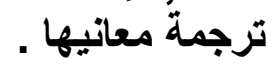

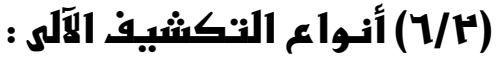

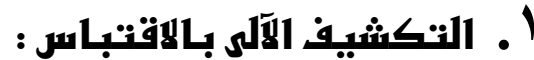

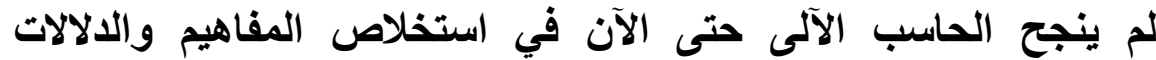

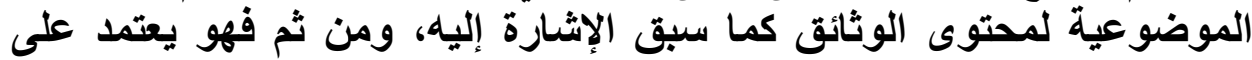

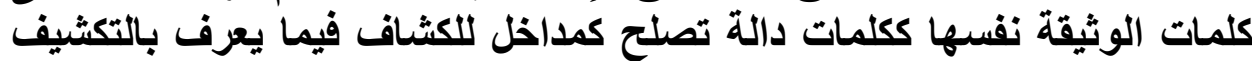

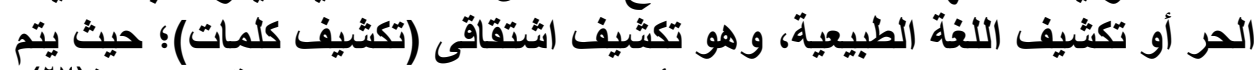
اشتقاق الكلمات من عناوين الوثائق أو من النص الكامل للوثيقة المكشفة(YV)

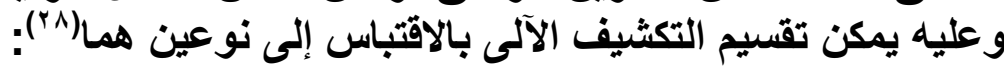

\section{أ- تكشيف الكلمات الدالة في السياق :}

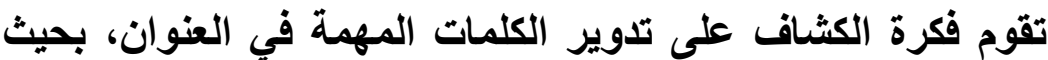

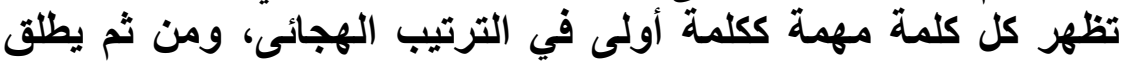

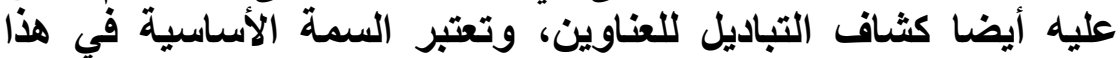

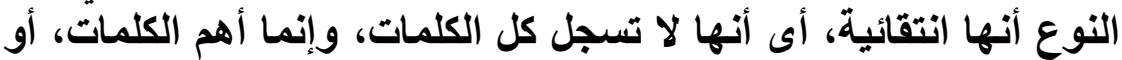
أكثرها دلالة على الموضوعات.

$$
\text { ب- تكشيف النصوص. }
$$

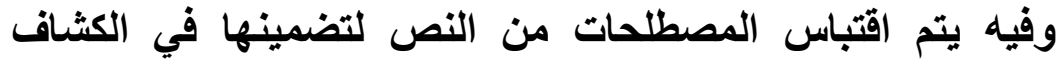

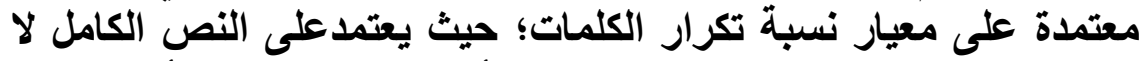

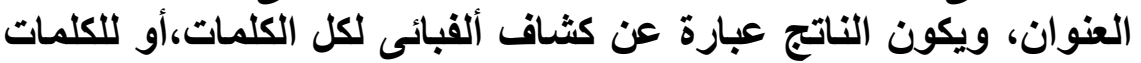


الرئيسية فقط باستثناء الكلمات الغير هامة مثل الدروف، فيقوم ببيان

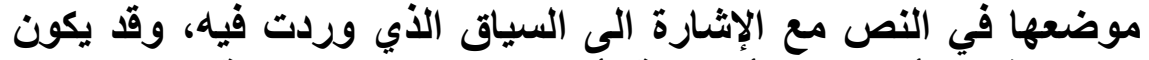

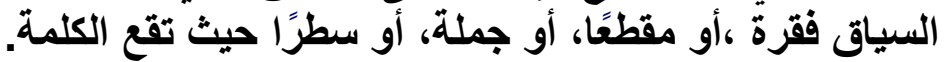

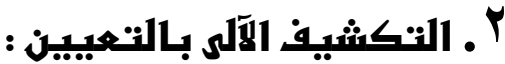

وهو عبارة عن إعداد مجموعة من السمات Profile لكل مصطلح يمكن

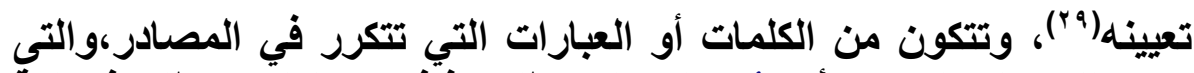

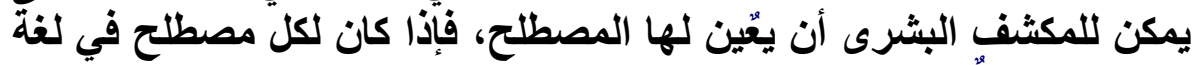

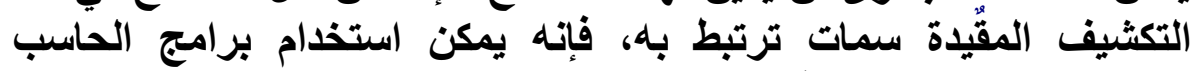

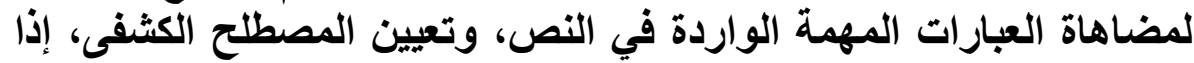

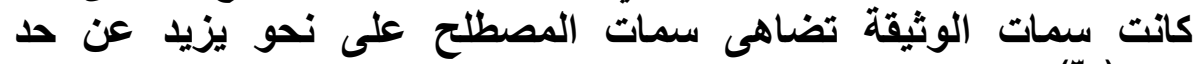
معين (r) كانب (r)

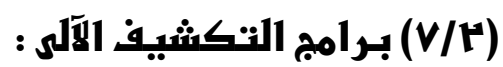

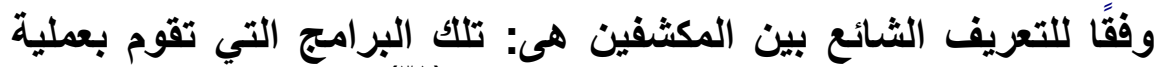

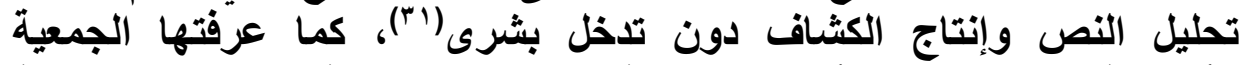

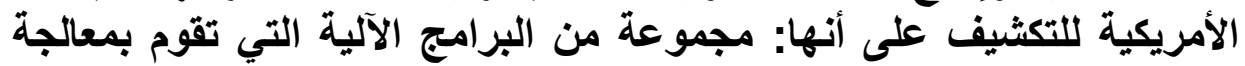

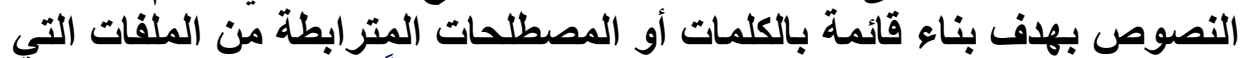

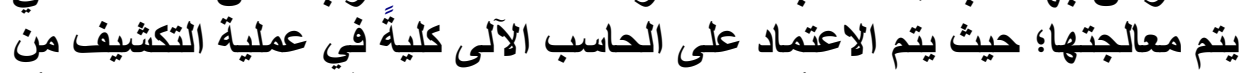

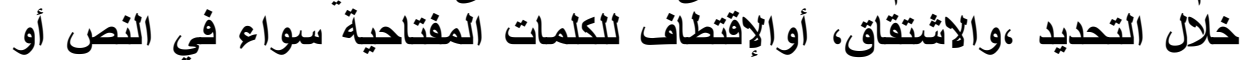

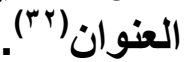
وهناك مجموعة من البرمجيات المعدة خصيصًا لهزا الغرض،لعل (أبرزها(T)

Kwic concordance for windows, Conc: A concordance generator for the Macintosh, Kwic concordance.

وقد اختلف الباحثون والمتخصصون بين هذه البرامج، وانقسموا ما بين مؤيد ومعارض؛ حيث أشار Seth A.Mislin إلى هذه النوعية من البرامج

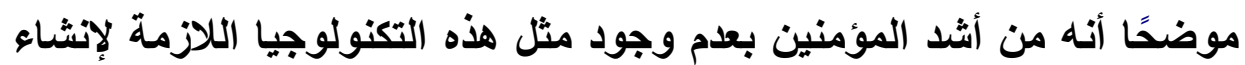

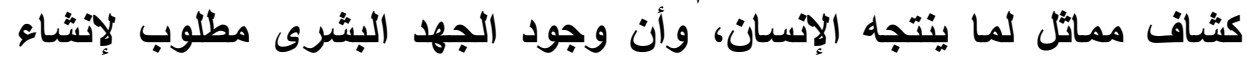

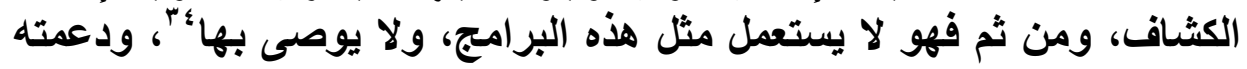
مan C. Wright

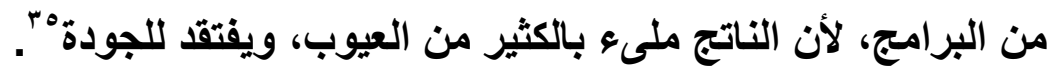

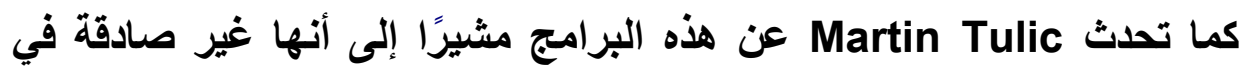
ادعائها، لأن الناتج عبارة عن قائمة بكلمات النص مع مؤشرات لأماكن 
وجودها، ومن ثم فهى أثبه بكثاف النص، ولا علاقة لها بما ينتجه البشر من

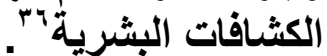

وفيما يتطلق بالجمعيات المهنية، فقل اتفقت كل من الجمعية الأمريكية

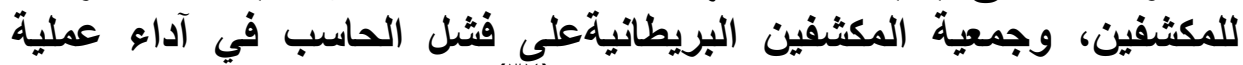

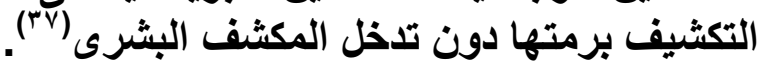

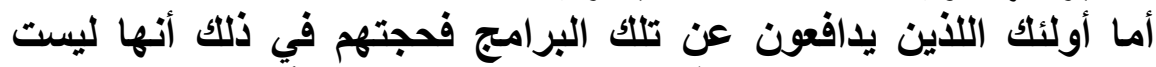

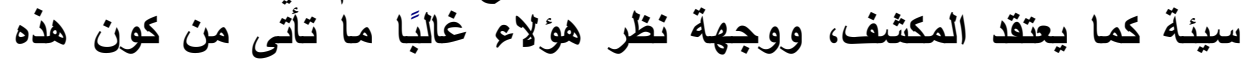

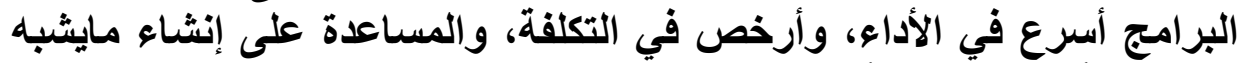

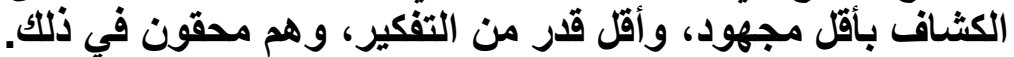

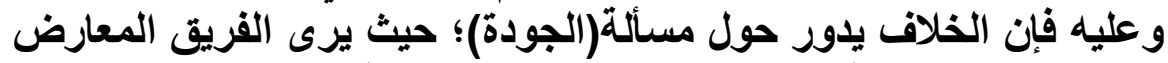

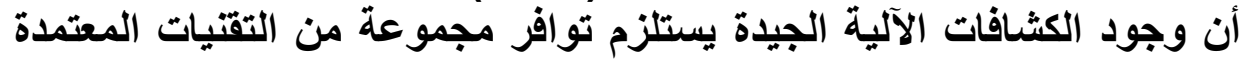

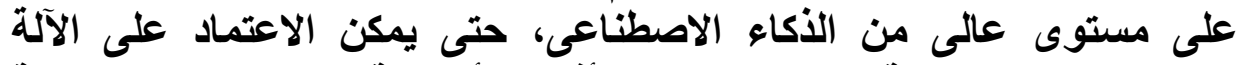

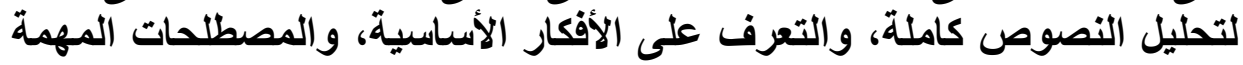
بها، وتحديد العلاقات بين المفاهيم ذات الترفي الصلة في جميع أنحاء النص، وهوات العهدة

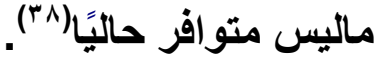

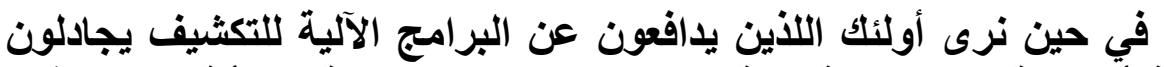

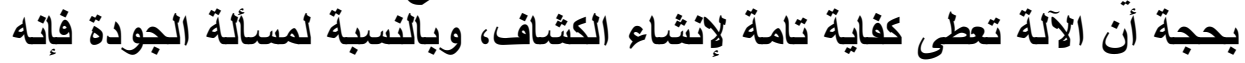

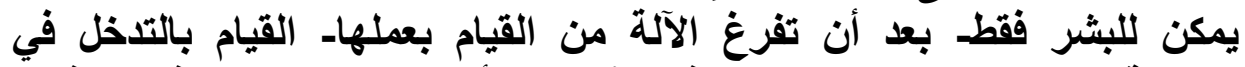

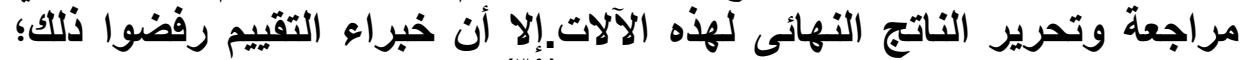

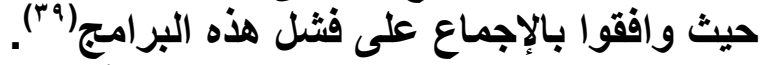
ينبغى الإشارة هنا إلى وجود نوع آلى آخر من البرامج يستخدماعه المكشفون

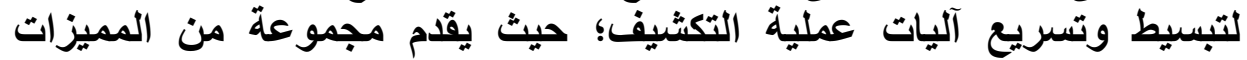

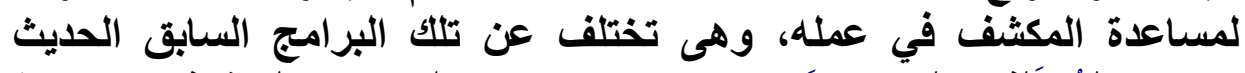

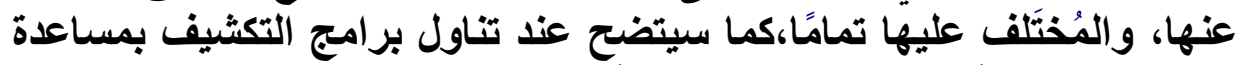

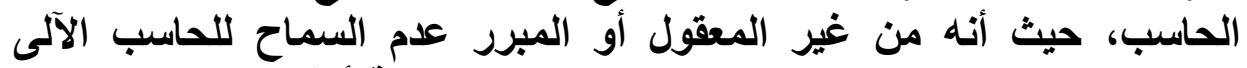

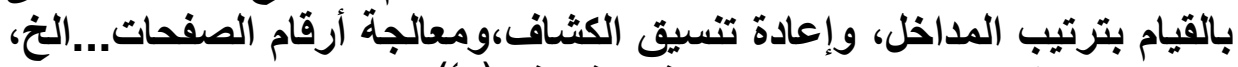

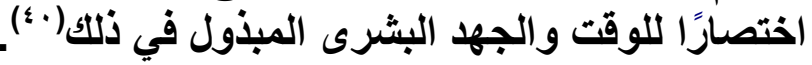

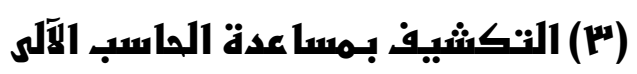
يعرف أيضًا بالتكثيف المؤتمت، ويقابله بالإنجليزية : automated indexing, Machine aided indexing, Semiautomatic indexing, computer- assisted indexing.

وقد تم تعريفه في قاموس ODLIS على أنه:أحد أنماط التكثيف التي يتم فيها برمجة الحاسب لاختيار المصطلحات الكثفية اعتمادًا على تحليل الكلمات 


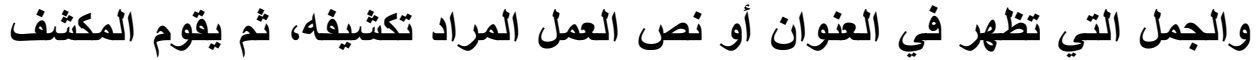

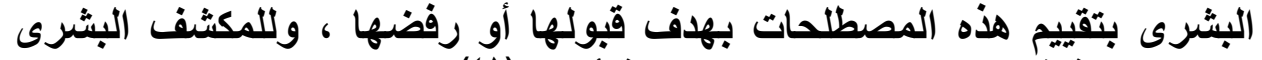

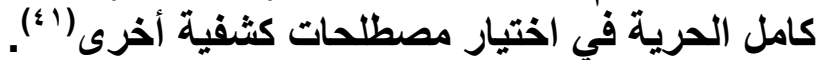

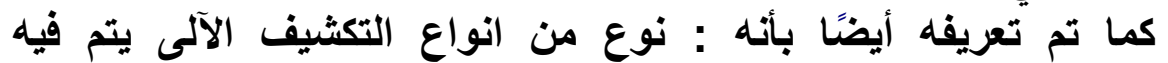

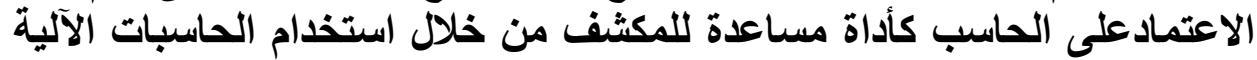

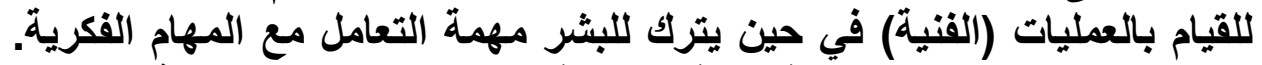

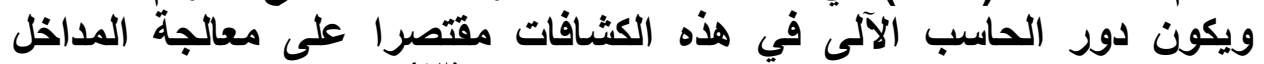

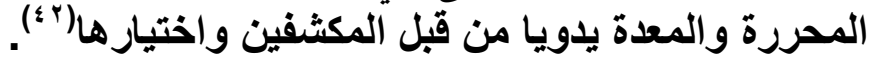

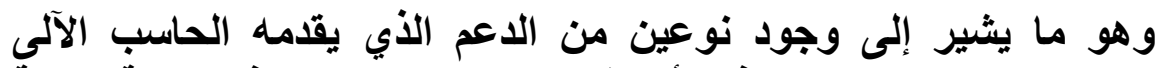
للمكثف لتعزيزعمله وتشريعاه، ذلك أن طرق إنى استخدام الحاسب في في ميكنة عملية التكشيف تنطوى على شقين :

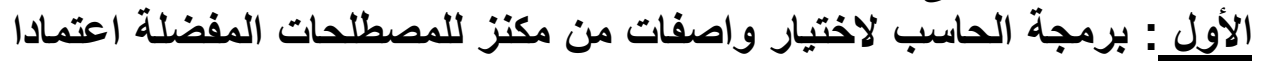

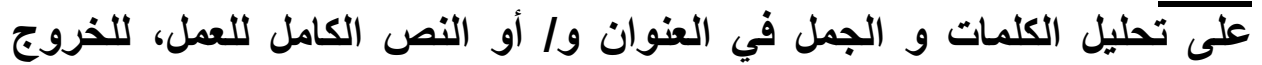

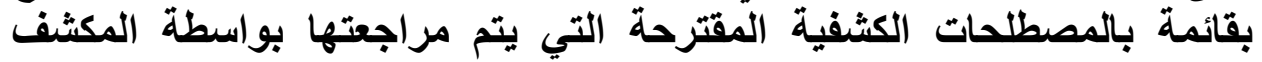

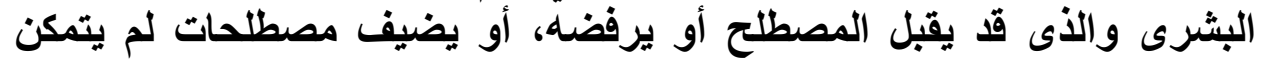
البرنامج من تعيينها.

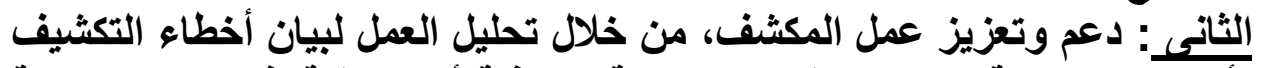

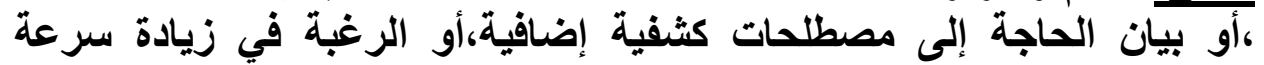
العمليات والوظائف التي يقوم بهان التها المكشف.

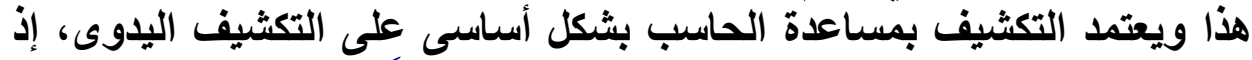

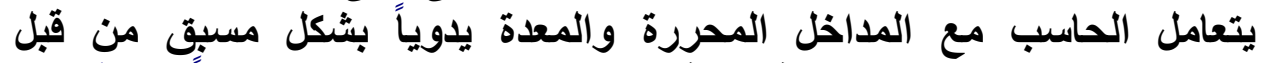

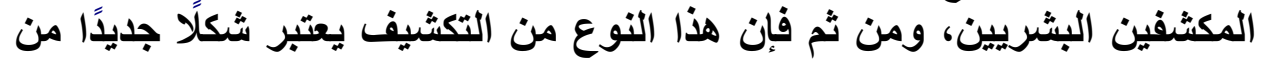

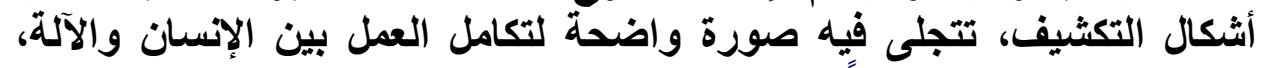
وتفادى عيوب ومساوئ كلاً منهما.

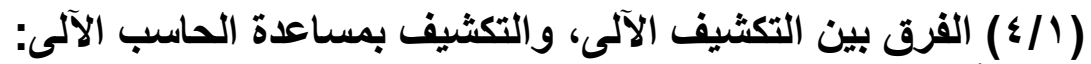

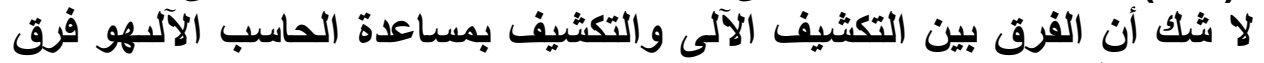

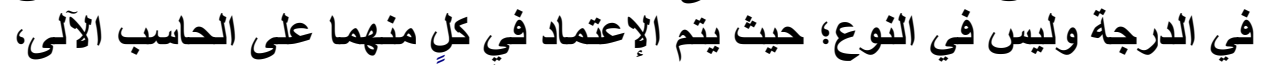

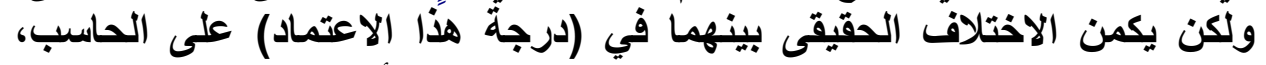

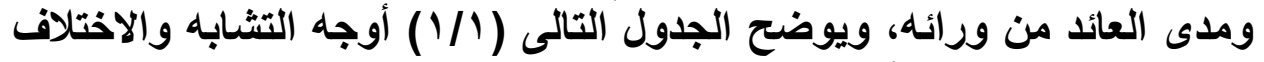
بين كلٍ من التكثيف الآلى والتكشيف ويور بمساعدة الحاسب. 
جدول (Y) : الفرق بين التكشيف الآلى، والتكشيف بمساعدة الحاسب الآلى.

\begin{tabular}{|c|c|c|c|}
\hline التكشيف بمساعدة الحاسب & التكشيف الآلى & والمقارنة & r \\
\hline 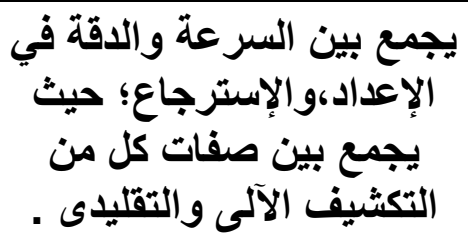 & 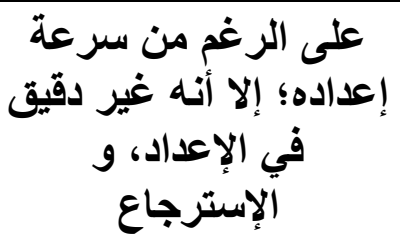 & والدرة & 1 \\
\hline 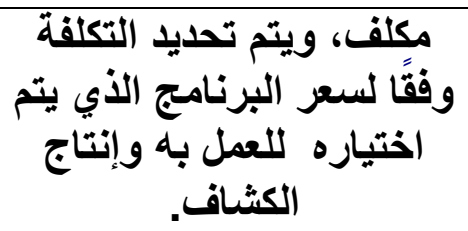 & قليل التكلقة & التكلقة & $r$ \\
\hline جيا جدا & بفاكثير للجودة ، وملئ & الجودة & $\mu$ \\
\hline 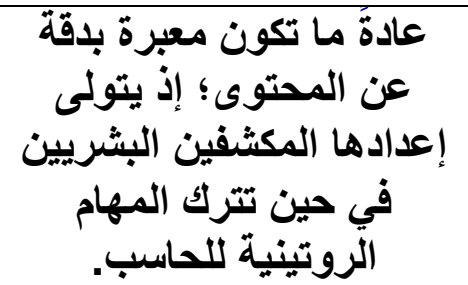 & قد تكون مضللة & المداخل & $\varepsilon$ \\
\hline على إحالات. & 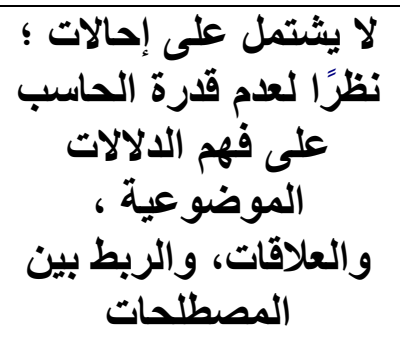 & الإحالات & 0 \\
\hline 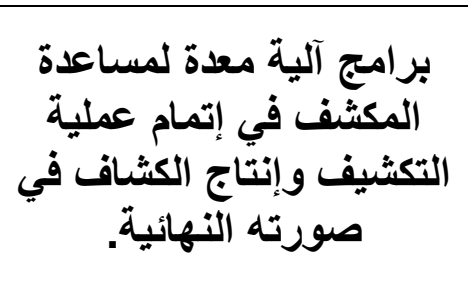 & 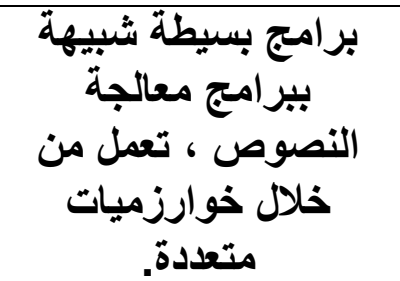 & البرامج & 7 \\
\hline
\end{tabular}


مجلة كلية الآداب، جامعة سوهاج، العدد الخمسون، الجزء الثاني، يناير 19 ـ ب م

\begin{tabular}{|c|c|c|c|}
\hline التكثيف بمساعدة الحاسب & التكشيف الآلى & وجها & b \\
\hline البشرى لتتفيذ المهام الفكرية العنصر & 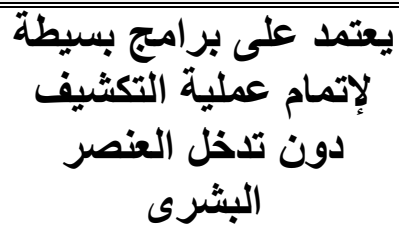 & 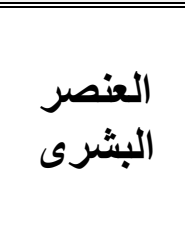 & V \\
\hline 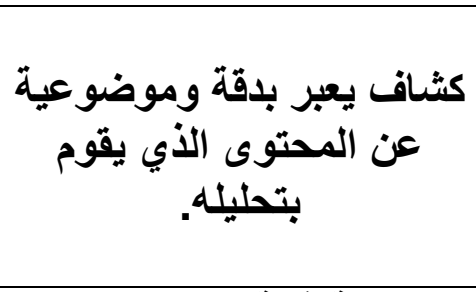 & 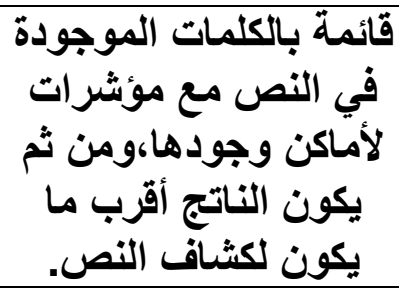 & & $\wedge$ \\
\hline 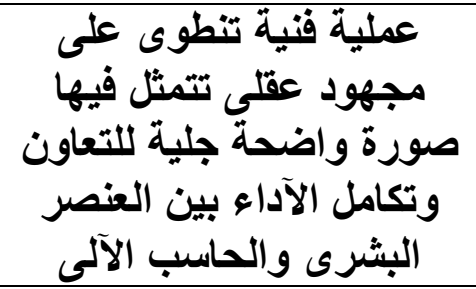 & علاصة آلية(ميكانيكية) & الوصف & 9 \\
\hline 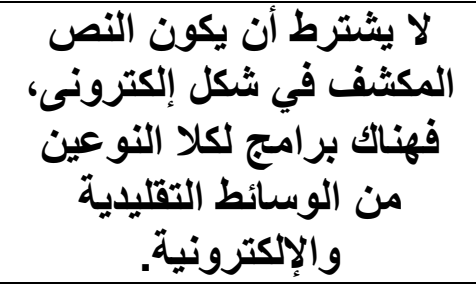 & المكثنزم وجي شي شكل النص & المكثف النص & 1 . \\
\hline يجب تصفح الكثاف للوصول المدخل المطلوب. & 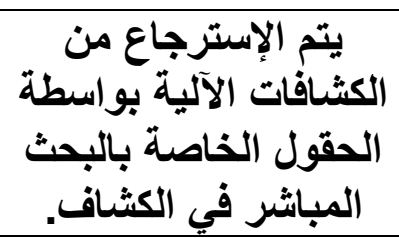 & الإسترجاع & 11 \\
\hline كشاف يعبر عن المحتوى بكل & قائمة بالكلمات الموجودة مؤشرات & النهائى & Ir \\
\hline
\end{tabular}


() التكشيف عملية فنية تنطوى على مجهود عقلى، وتتم وفقا لقواعد

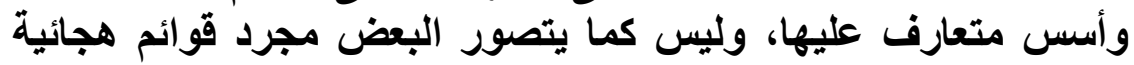

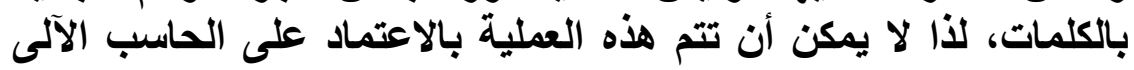

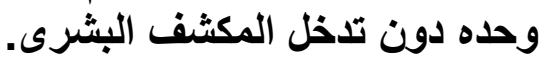

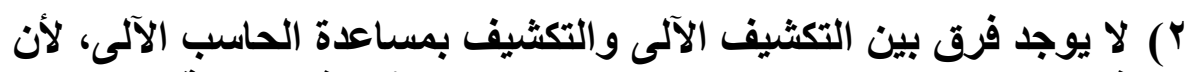

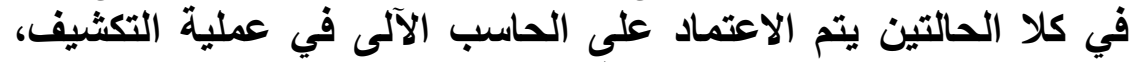
لكن الفرق الحقيقى يكمن في درجة هذا لاعني الاعتماد. 
مجلة كلية الآداب، جامعة سوهاج، العدد الخمسون، الجزء الثاني، يناير 9 ـ ب م

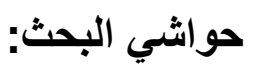

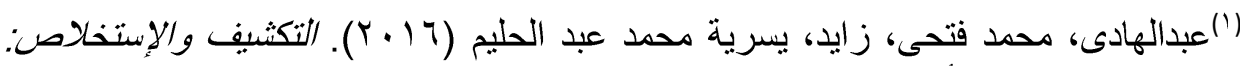

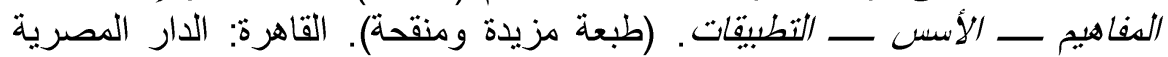

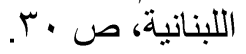

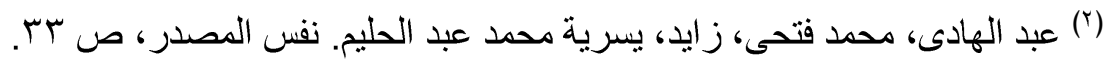

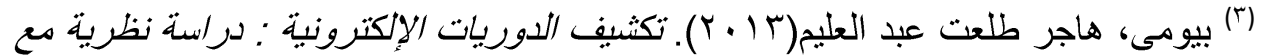

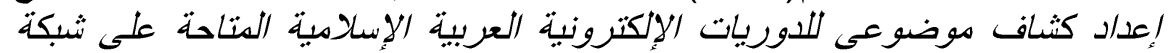

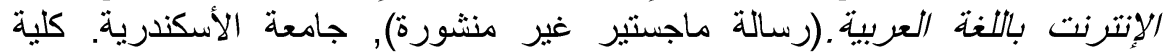

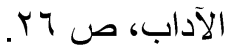

(4).American Society for indexing.About Indexing(on line article), Access date 21 Feb 2017. Retrievedfrom : http://www.asindexing.org

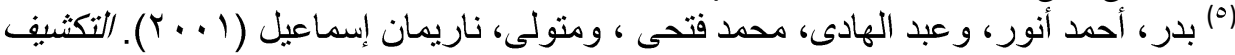

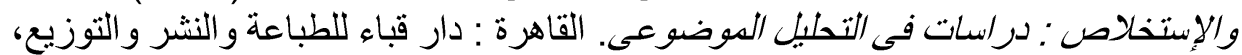
ص ص و (T)

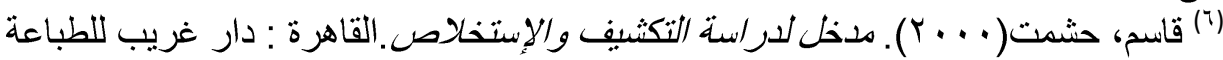

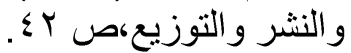

(7) Cleveland, Donald B \& Cleveland, Ana D (2013).Introduction to Indexing and Abstracting.(4ed).Santa Barbaras Calif : Libraries Unlimited, P16.

(8) Maislin,Seth A. (2013). Notes on Automatic Indexing (online article). Access date 21 Feb. 2017, Retrievedfrom: http://taxonomist.tripod.com/indexing/autoindex.html

(9) Birger, Hjorland (n.d) .Automatic indexing. Access date $12 \mathrm{Feb}$ 2017.Retrievedfrom:

http://www.iva.dk/bh/lifeboat_ko/CONCEPTS/automatic_indexing.htm.

(10) Li ,Yu-qin, Wang, Lei , and Shi, Shui-cai (2016), Research and Application to Automatic Indexing. Access date 1 Feb 2017, Retrievedfrom:

http://link.springer.com/chapter/10.1007/978-3-642-13318-3_41

(11) Lancaster F.W (1991).Indexing and abstracting in theory and practice. London: Library Association,p.57.

(12) Moens, MarieFrancine (2010).Automatic Indexing and Abstracting of Document Texts.The Information Retrieval Series, 6064, p. 336.

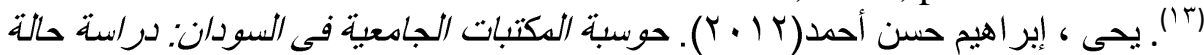

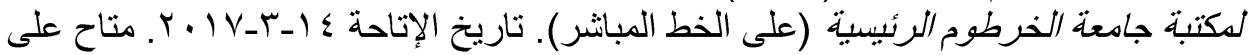

$$
\begin{aligned}
& \text { http://hdl.handle.net/123456789/1020: }
\end{aligned}
$$




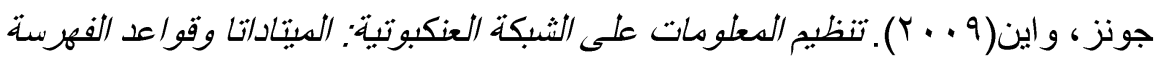

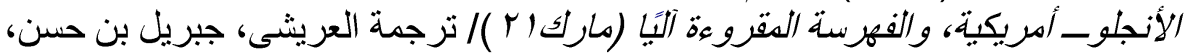

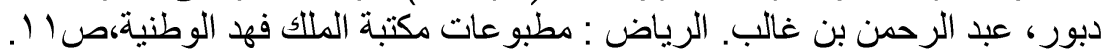

(15) Fetters, Linda K (2013).Handbook of Indexing Techniques: A Guide for

Beginning Indexers. (Fifth ed). oxford: Information Today, Inc, p.15.

${ }^{(16)}$ Cleveland, Ana D \&Cleveland, Donald B (n.d). indexing with

Microcomputer: past, present and future. Access date 20 Feb.

2017, Retrievedfrom:

http://web.simmons.edu/ chen/nit/NIT'90/091-clea.html

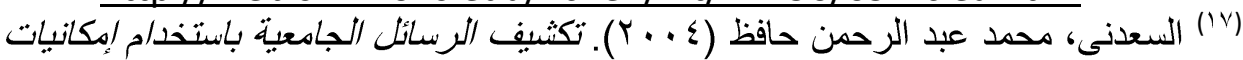

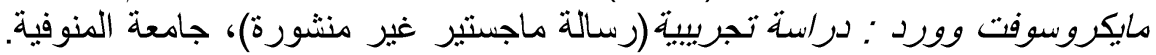

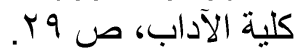

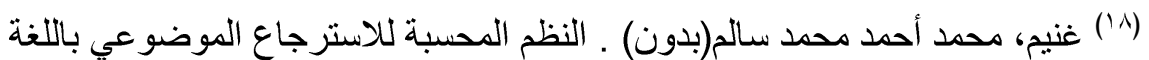

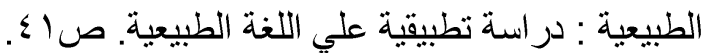

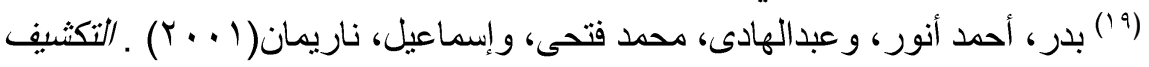

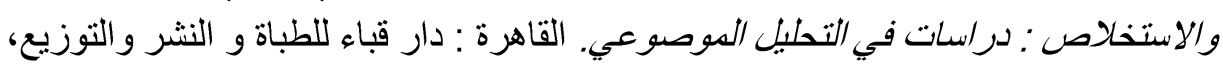
ص ص

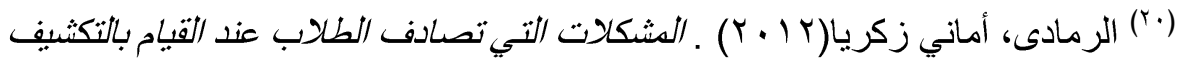

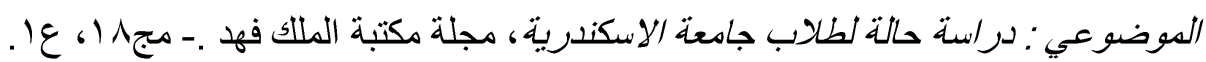
ص מ ror

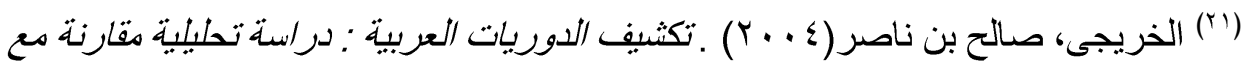

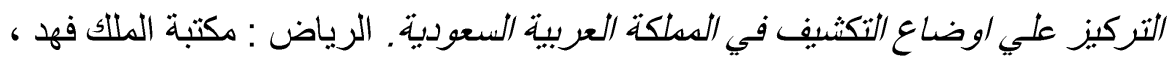
ص.

(22) Obaseki, Tont 1 .March2016 Library Philosophy and practice .

Automated Indexing:The Key to Information Retrieval in the $21^{\text {st }}$ century.

P2-3.

(23) Wright. Jan C. 1998 an overview of indexing methods . (

:http://www.wrightinfromation.com/indexmethod.pdf ) (cited : 15 April

2016 )

(24) Maislin, seth A. July 2002. Notes on Automatic Indexing,

URL[http://taxonomist,tripod.com/indexing/autoindex.html][cited:16

April2016]

(25) Tulic, Martin.op.cit.

${ }^{(26)}$ Meyers, William P. Indexing book: lesson in language computations, part1.-KeyWords,V.13,no.2(April-June2017). Part20-Key Words, 7, 13, no 3(July - Septamber20016).

URL : http//www. Openicon .com/indexing_white_Paper1html 
مجلة كلية الآداب، جامعة سوهاج، العدد الخمسون، الجزء الثاني، يناير 19 • ب م

(27) Wan, X., Xiao, J. (2010).Exploiting neighborhood knowledge for single document summarization and keyphrase extraction[J]. ACM Transactions on Information Systems (TOIS), 28(2), p.8.

(28) Zhang, C., Wang, H., Liu, Y. (2008). Automatic Keyword Extraction from Documents Using Conditional Random Fields. Journal of Computational Information Systems, 4(3).p.47.

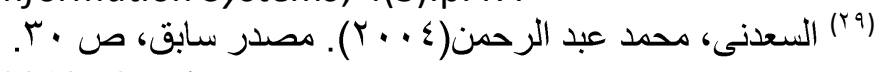

(30). Fetters, Linda K (2013).Op.cit.P.55.

(31).Mislin, Seth A.Op.cit.accessed 20/3/2017.

${ }^{(32)}$.American Society for Indexing.Op.cit .accessed 4/3/2017.

${ }^{(33)}$ Tulic, Martin (n.d).Op.cit .accessed 20/2/2017.

${ }^{(34)}$.Mislin, Seth A.Automatic Indexing.Op.cit. accessed 20/2/2017.

${ }^{(35)}$.Wright, Jan C.An Overview of indexing methods (n.d). (online article). Access date 12 Apr 2017. Retrieved from: http://www.wrightinformation.com/indexmethod.pdf

${ }^{(36)}$.Tulic,Martin.Automatic Indexing.Op.cit.accessed 20/1/2017.

${ }^{(37)}$.Society of indexers.FAQs about indexes and indexing.accessed 4/1/2017..at:

http://www.socind.demon.co.uk/indexing/FAQs.htm\#FAQ1

${ }^{(38)}$.Lamb, J.(2008). Human or computer produced indexes?, Society of Indexers. (online article). Access date 5 May 2017. Retrievedfrom: http://www.indexers.org.uk/index.php?id=463

${ }^{(39)}$ J.D. \& Carballo, Perez (2001).The nature of indexing: How humans and machines analyze messages and texts for retrieval. Part 1\&2: Research and the nature of human indexing. Information processing and management, 37(2), 237.

${ }^{(40)}$.Dedicated indexing software: what it can do for you?(2012). (online article),Access date 2 Jan 2017. Retrievedfrom:

http://www.indexers.org.uk/files/publications/Indexing\%20Softwar e\%20programs\%20v2.pdf

${ }^{(41)}$.Reitz, Joan M. Op Cit. Access date 12/1/2017.

${ }^{(42)}$. Moens, Marie Francine. Op.cit.p.42. 